\title{
Aspilia spp. Leaves: A Puzzle in the Feeding Behavior of Wild Chimpanzees
}

\author{
R. W. WRANGHAM \\ The University of Michigan \\ and T. NISHIDA \\ The University of Tokyo
}

\begin{abstract}
Unlike other chimpanzee food items, the leaves of Aspilia pluriseta, $A$. rudis and $A$. mossambicensis (Compositae) are eaten without being chewed. Moreover, A. pluriseta and A. rudis are eaten slowly and singly and particularly in the early morning. This unusual behavior suggests that Aspilia leaves offer peculiar stimuli, perhaps with pharmacological effects.
\end{abstract}

\section{INTRODUCTION}

Young leaves of a particular herb genus (Aspilia, Compositae) were found to be eaten in an unusual manner by wild chimpanzees. They were usually eaten slowly and singly (at one study site) without being chewed (at both sites). Since feeding efficiency on these leaves is considerably lower than that on other leaves, it is possible that the leaves contain rare nutritive or non-nutritive compounds or elements, which may be attractive to chimpanzees. Nutritional analysis of Aspilia leaves are not available, and are unlikely to be rewarding until there are clues as to which class of compounds or elements are relevant. However, we present our observation here, to stimulate further studies of this unusual feeding behavior.

\section{METHOD}

Two population of chimpanzees were observed, both at Tanzanian sites on the shore of Lake Tanganyika. R. W. W. studied two social groups in Gombe National Park in 1972 and 1973. The study site was described by Goodall (1975), WRANGHAM (1977) and ClutTONBRocK and GiLleTt (1979). Individual adult males were observed as focal animals for up to $13 \mathrm{hr}$ continuously. Their behavior was recorded every minute as a point-sample (ALTMANN, 1974); their companions' behavior (i.e., all chimpanzees within $100 \mathrm{~m}$ ) was recorded every 5 min. Observations were made in all months except February, March and April, and totalled $1,026 \mathrm{hr}$. Additional data come from the observations of numerous trained assistants working in Gombe between 1964 and 1973.

T. N. studied two social groups in the Mahale Mountains from 1965 to 1979 . The study site was described by NishIDA (1968) and NiSHIDA and UeHARA (1981). Observations were made mostly by ad-lib sampling (AltmanN, 1974), and the data presented here are from recent observations of one group (K-group) totalling 1,242 hr as follows: $95.5 \mathrm{hr}$ (1974), 250.5 hr (1975), 439.8 hr (1976), 149.1 hr (1977) and 307.0 hr (1979). 
In both studies chimpanzees were habituated to the presence of observers. Plants were identified by Drs. J. B. Gillett and C. KABUYE of the East African Herbarium, Nairobi. In Gombe it was not always possible to distinguish the two species of Aspilia in the field, and they are therefore considered together.

\section{RESULTS}

\section{FeEding TeChNIQUE}

Chimpanzees ate young leaves from many different species of herbs, shrubs and trees (Gombe, 54 species, Wrangham, 1977; Mahale, 117 species, Nishida \& Uehara, 1983). Most of these were eaten quickly and continuously: leaves were picked singly or stripped in numbers off the stem, and added to those already being chewed. Clear exceptions to the normal leaf-eating method occurred in only three cases. These were Aspilia pluriseta gondensis (O. Hoffm.) WILD, A. rudis OLIV. and HieRN (both found only in Gombe) and A. mossambicensis (OLIV.) WILD (found at Mahale). Leaves of all the Aspilia species are eaten without being chewed, although those of $A$. mossambicensis are picked off in a usual manner described above (Fig. 1).

All are herbaceous straight-stemmed plants up to $1.5 \mathrm{~m}$ tall, occurring in grassland or deciduous woodland. In Mahale, A. mossambicensis tended to occur in Bauhinia petersiana thicket on valley slopes or near the shore of Lake Tanganyika. Their leaves have a rough surface and no very striking taste to humans. Only young leaves were eaten, between about $2 \mathrm{~cm}$ and $10 \mathrm{~cm}$ long, and up to about $4 \mathrm{~cm}$ broad. At Gombe, feeding was normally preceded

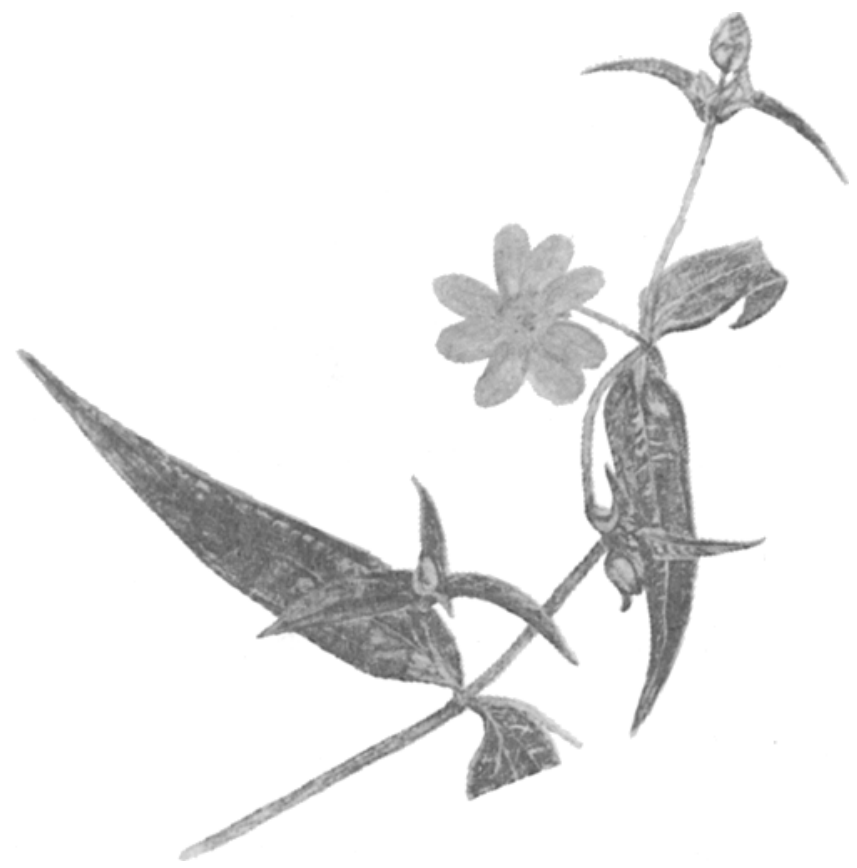

Fig. 1. Aspilia mossambicensis (OLIv.) WiLD found in Mahale. (Drawn by M. UeHARA) 
by a careful visual inspection and sometimes by "tasting" with the lips; chimpanzees closed their lips over a leaf on several occasions, and once did so six times before picking it.

At both sites, either the whole leaf or (more usually) the distal half was selected. At Gombe, it was normally picked only after the previous leaf had been swallowed, and typically one leaf was taken at a time. (On a few occasions, however, a chimpanzee stripped five or six leaves from the stem by a single movement of one hand.) Instead of chewing the leaf, the chimpanzees would take it into its mouth on the tongue, and appeared to rub it against the upper palate, often leaving the jaw slack. Jaw movements observed when the mouth was closed also suggested that the leaves were being rolled around. Once the leaf was seen being folded inside the mouth by the tongue, and on two occasions leaves of $A$. rudis were folded before being put in the mouth. No chewing with the teeth was seen.

The lack of chewing indicated that the leaf was unlikely to be damaged much by being eaten. This was confirmed by faecal analysis. In Mahale, entire leaves or halves of leaf were found regularly in chimpanzee faeces (Table 1) and showed no evidence of having been chewed. Faeces contained up to 50 leaves $(\bar{x}=9.2, N=17)$. In Gombe also the only leaves identified during faecal analysis between 1964 and 1967 were those of Aspilia spp., found in 19 months. (Faeces were not examined subsequently.)

Leaves were usually swallowed without any special facial expressions by the chimpanzee. During one eating bout of Gombe, however, an adult male wrinkled his face above the nose as he swallowed. He did this with 3 out of 45 leaves, and the rest were swallowed normally. While wrinkling his nose the male appeared to be inhaling.

Table 1. Monthly variation in the per cent of faeces containing A. mossambicensis leaves.*

\begin{tabular}{|c|c|c|}
\hline Month & $\%$ faeces with $A$. rudis leaves & $\begin{array}{l}\text { Sample size } \\
\text { (No. of faeces) }\end{array}$ \\
\hline January & 10.5 & 114 \\
\hline February & 12.2 & 115 \\
\hline March & 1.7 & 235 \\
\hline April & 0.0 & 199 \\
\hline May & 1.0 & 195 \\
\hline June & 0.0 & 235 \\
\hline July & 1.6 & 320 \\
\hline August & 2.6 & 274 \\
\hline September & 0.9 & 218 \\
\hline October & 1.0 & 105 \\
\hline November & 0.5 & 204 \\
\hline December & 1.1 & 95 \\
\hline
\end{tabular}

*Data were collected in the Mahale Mountains from 1975 to 1979 by T. NishidA, S. Uehara, M. Hrraiwa, R. Nyundo, M. Seifu, J. Katensi and A. Kasulamemba.

\section{FeEding Rate}

Feeding rate when eating Aspilia spp. leaves at Gombe was slow for two reasons. Only one leaf was normally eaten at a time, and each leaf was itself eaten slowly. Ingestion rates in different bouts at Gombe varied from 2.4 per minute for large leaves ( $N=40$ leaves) to 15.4 per minute for small leaves (ca. $2 \mathrm{~cm}, N=16$ leaves). The median rate was 5.0 per minute, i.e., a leaf every $12 \sec (N=7$ bouts); this was the same rate of leaf-eating as occurred in the only timed bout in Mahale. 
The number of minutes spent eating Aspilia spp. leaves was recorded at Gombe on ten of the days when it was eaten, and varied from less than $1 \mathrm{~min}$ to $25 \mathrm{~min}$ per individual (median 15 min or 75 leaves). On most occasions there were many young leaves still available when the chimpanzees left the patch. This contrasts with many species of herbaceous leaf, for which all the young leaves available were commonly consumed in one session.

\section{DiURNAL VARIATION}

Most chimpanzee foods were eaten throughout the day. However, although this was true of Aspilia mossambicensis in Mahale, the Gombe data showed a striking exception. First, the time of 46 bouts of eating A. mossambicensis was recorded in Mahale. Eating occurred from $9: 11$ to $19: 43$, and appeared to be evenly distributed across the day, or possibly biassed towards the afternoon when the diurnal variation in observation time was taken into account. By contrast, all bouts of eating Aspilia spp. at Gombe fell between 6:30 and 7:45 with a median point at 7:15 $(N=20)$. Thus in Gombe feeding on Aspilia spp. leaves was virtually restricted to the first hour after dawn. This occurred even when there were no Aspilia leaves close to the nest site: on at least five occasions chimpanzees made detours (up to 5-min walking) directly to an Aspilia patch, before travelling in a different direction to eat fruits or other foods. No other foods were eaten at such confined times, though diurnal variation occurred in the eating of some other items. For instance, in general leaves were eaten later in the day than fruits (Wrangham, 1977). The clearest example was Ficus exasperata VAHL (Moraceae) which in 12 bouts at Gombe was eaten between 15:00 and 20:00 with a median midpoint at 17:00. Aspilia spp. leaves were the only leaves eaten most in the morning at Gombe.

\section{FREQUENCY OF EATING}

In Gombe Aspilia spp. leaves were eaten in ten bouts during 1,026 hr, i.e., one feeding bout per $102.6 \mathrm{hr}$. Direct observation and fecal analysis showed that Aspilia spp. leaves were eaten in all months except April and November. In three months of focal observation (July 1972, probably $A$. pluriseta; December 1972 and January 1973, probably $A$. rudis) chimpanzees were observed on 22 mornings, and they ate Aspilia spp. leaves on 8 of them, or $36.4 \%$. On 2 of the 14 mornings when they did not eat Aspilia spp. leaves, chimpanzees encountered a patch without showing interest in it.

In Mahale $A$. mossambicensis leaves were eaten on 18 occasions in 1,242 hr. i,e., once per $69.0 \mathrm{hr}$. Feeding was recorded in all months, but was commonest after the beginning of the wet season. This is illustrated in Table 1, which shows a peak in the eating of $A$. mossambicensis in January and February. The frequency and seasonal occurrence of eating Aspilia spp. leaves were therefore similar in Gombe and Mahale.

\section{Association with FeEding on OTHer ITEMS}

In Gombe Aspilia spp. leaves were eaten both in periods of food abundance (e.g., January 1973) and food scarcity (e.g., July 1972, WRANGHAM, 1977). To find out if Aspilia spp. leaves tended to be eaten in conjunction with particular other foods, those eaten immediately before 
and after Aspilia bouts were recorded. On most days (15 out of 22, i.e., 68\%) Aspilia spp. leaf was the first food eaten. On the remainder the foods eaten before it were all different, and included fruits of five species and leaves of two species.

Those eaten after Aspilia bouts were recorded on ten days. Food selection again appeared to be varied. Nine different foods were eaten, comprising five fruits, two leaves, one seed and one flower. All were typical for the season.

If Aspilia spp. leaves provided insignificant calorific value, it might be expected that the total feeding time per day would be greater when they were eaten (Aspilia-days) than when they were not eaten (non-Aspilia-days). To test this the number of minutes spent feeding before 12:00 was scored on Aspilia-days, and matched to the same measure from the nonAspilia-day closest in date (maximum difference was one week). Eight pairs of Aspilia-days and non-Aspilia-days were obtained. On Aspilia-days the median number of minutes spent feeding before 12:00 was 178, of which 15 were spent on Aspilia spp. leaf. On non-Aspiliadays the median was $129 \mathrm{~min}$. This suggests that more time was spent feeding on Aspiliadays (Wilcoxon $T=4, N=8, p<0.05$, two-tailed). However, in view of the considerable variation in feeding time per day (WRANGHAM, 1977) this result must be treated with caution until a larger sample size is available.

\section{INDIVIDUAL VARIATION}

No evidence was obtained of individual variation in the tendency to eat Aspilia spp. leaves. In Gombe a total of 21 individuals was recorded eating it, including both sexes from two different social groups (Kasekela and Kahama communities, Goodall, 1975). The youngest was a 2-year-old female, and the oldest was a senescent male of about 40 years. Differences in the number of Aspilia observations per individual were explicable by differences in observation time. The same was true in Mahale, where 12 individuals, of both sexes, were seen to eat $A$. mossambicensis.

Normally all the chimpanzees present at an Aspilia spp. patch ate leaves. On two occasions when this was not the case those who did not eat were individuals who ate leaves on other days.

\section{DISCUSSION}

The results show that feeding on Aspilia spp. leaves was peculiar in two principal ways. First, chimpanzees ate each leaf slowly and individually (but not in Mahale), rolling and pressing them around the mouth, and did not chew them. Second, in Gombe they ate them only in the early morning.

Without chewing, the massaging of plants in the mouths and digestive tracts of vertebrates might release the cell contents, and even if the plant cell walls remain intact, nutrients may be extracted through the stomach by the enzymes and microorganisms of the digestive tract. However, chewing is a powerful and effective way of digestion. Why do chimpanzees refrain from chewing these particular species of leaves and not others? This remains a puzzle. We are not aware of any other animals which eat leaves without chewing them.

However, it seems clear that Aspilia leaves could not have provided sufficient calorific value to merit the time taken to find and eat them, given that foods such as ripe fruits were 
available on the same days. Probably, the young leaves may contain nutritive or non-nutritive compounds attractive to chimpanzees, the concentration of which could vary with the time of day at least at Gombe, as RoBINSON (1974) found for alkaloids in the leaves of three species (though it is surprising that the Gombe and Mahale populations differed in this respect).

No chemical analysis of Aspilia leaves is available, but ethnomedicine suggests that there may be pharmacological agents in Aspilia leaves. Thus, WATT and GERDINA (1962) mention the medical use of the root and leaves of Aspilia by African people; "The Shambala drink an extract of the root of Aspilia holstii O. HofFM. for the relief of lumbago, sciatica and neuralgia. The Pare use the plant along with Hymenodictyon parvifolium as a remedy for threatened eclampsis, the mode of application ensuring free perspiration. In Tanganyika, one of the indigenous galactagogues, for both human and cattle, is made from the leaf and root."

JANZEN (1978) listed many anecdotal but suggestive cases of the use of secondary compounds as a medicine by mammals. HAMILTON, BUSKIRK and BUSKIRK (1978) pointed out one suspected case of drug use by primates (Papio ursinus eating Datura spp.). In the present case it seems unlikely that Aspilia leaves were used as a source of medicine since there was little individual variation in eating it. The possibility that Aspilia leaves provided attractive stimulants is supported by the increased feeding time on mornings when chimpanzees ate Aspilia leaves at dawn.

More data are needed to elucidate the significance of eating Aspilia spp. leaves. The unusual way of eating them, and the geographical difference in the time of days when they were eaten suggest that further investigation would be valuable.

Acknowledgements. We are grateful to the Tanzanian Government for their permission to work in Gombe National Park and the Mahale Mountains. Fieldwork in Gombe was financed by the Grant Foundation, and Dr. J. Goodall and Prof. D. A. Hamburg provided field facilities. Fieldwork in Mahale was funded by the Ministry of Education, Science and Culture, Japan and the Japan International Co-operation Agency. We thank Drs. S. Uehara and T. Iwamoto for critical comments, and Mrs. Uehara for permission to use the painting.

\section{REFERENCES}

Altmann, J., 1974. Observational study of behavior; sampling methods. Behaviour, 48: 1-41.

Clutton-Brock, T. H. \& J. B. Gilletr, 1979. A survey of forest composition in the Gombe National Park, Tanzania. Afr. J. Ecol., 17: 131-158.

Goodall, J., 1975. Chimpanzees of Gombe National Park: thirteen years of research. In: Hominization und Verhalten, G. KurTh \& I. Eibl-Eibesfeldt (eds.), Gustav-Fischer Verlag, Stuttgart, pp. 74-136.

Hamiton, W. J., III, R. E. Buskirk \& W. H. Buskirk, 1978. Omnivority and utilization of food resources by chacma baboons, Papio ursinus. Amer. Naturalist, 112:911-924.

JANZEN, D. H., 1978. Complications in interpreting the chemical defences of trees against tropical arboreal plant-eating vertebrates. In: The Ecology of Arboreal Folivores, G. G. MoNTGOMERY (ed.), Smithsonian Institution Press, Washington D.C., pp. 73-84.

Nishida, T., 1968. The social group of wild chimpanzees in the Mahali Mountains. Primates, 9:167227.

\& S. Uehara, 1981. Kitongwe name of plants. A preliminary listing. Afr. Study Monogr., 1: 109-131.

\& -1983 . Natural diet of chimpanzees (Pan troglodytes schweinfurthii): Longterm record from the Mahale Mountains, Tanzania. Afr. Study Monogr., 3: 109-130. 
RoBinson, T., 1974. Metabolism and function of alkaloids in plants. Science, 184: 430-435.

Watt, J. M. \& M. Gerdina, 1962. The Medicinal and Poisonous Plants of Southern and Eastern Africa (2nd ed.), E. \& S. Livingstone Ltd., Edinburgh \& London.

Wrangham, R. W., 1977. Feeding behaviour of chimpanzees in Gombe National Park, Tanzania. In: Primate Ecology, T. H. Clutton-Brock (ed.), Academic Press, London, pp. 503-538.

—Received August 30, 1982; Accepted December 7, 1982

Authors' Names and Addresses: R. W. Wrangham, Department of Anthropology, The University of Michigan, Ann Arbor, Michigan 48109, U.S.A.; T. Nishida, Department of Anthropology, Faculty of Science, The University of Tokyo, Bunkyo-ku, Tokyo, 113 Japan. 